the Brotherhood of Railway Conductors; Mr. O'Connell and Mr. Lennon of the American Federation of Labor and the chairman, Mr. Walsh. The report recommended a health insurance system for all interstate employees. As to the effect on the individual, it is far from being socialistic. It is more like the public schools; it encourages individual effort and it promotes individual success by making the individual more economically independent and able to take care of other necessities of life. Furthermore, the workman will own these funds, they will be part his; he will be running them and their management will be democratic. The workman will be entitled to the benefits which will be in no way a charity.

Dr. I. M. Rubinow, New York: Dr. Delphey makes certain definite statements, as, for instance, that neither workmen, employers nor physicians want this thing.

As far as the relation of organized labor to health insurance is concerned, Dr. Warren has already answered it. I would also like to inform Dr. Delphey that after Mr. Holland, the chairman of the New York Federation of Labor, had opposed a bill at Albany on March 14, he was reprimanded very severely by the New York Central Labor Union for his attitude in the matter.

As to the attitude of employers, the National Association of Manufacturers a few weeks ago came out very strongly in favor of compulsory health insurance applied to all wage workers. And as far as the medical profession is concerned, the statement of President Blue yesterday, and official statements by the House of Delegates, place the medical profession or at least that part of it represented in the American Medical Association, on record.

\section{SOME BACTERIOLOGIC OBSERVATIONS ON EPIDEMIC POLIOMYELITIS}

\section{PRELIMINARY REPORT * \\ GEORGE MATHERS, M.D. \\ CHICAGO}

During the past months poliomyelitis has been mildly epidemic in Chicago, and the relatively large number of fatal cases indicates that the current infection is highly virulent. In the work discussed briefly here the brain and cord were removed under sterile conditions as soon after death as possible, and cultures made immediately. Small pieces of tissue, which had been washed thoroughly, were macerated in sterile normal salt solution and the emulsion inoculated into various mediums, as, for example, ascites fluid and ascites dextrose agar containing a small piece of sterile rabbit kidney, ${ }^{1}$ ascites dextrose broth, and coagulated normal horse serum, both aerobically and anaerobically. The cultures were incubated at $35 \mathrm{C}$. for from one to seven days.

In seven of the eight cases examined thus far bacterial growth developed in the aerobic ascites dextrose broth and agar cultures after eighteen hours, while in the anaerobic cultures a definite growth usually did not appear until after from three to seven days, and then often very scantily. In six of the seven instances a pure culture of a gram-positive micrococcus was obtained. In one instance the cultures gave also a gram-negative bacillus.

The coccus grows rapidly in aerobic ascites dextrose broth as a granular material along the side of the tube, gradually settling to the bottom as a white flocculent sediment. In the anaerobic cultures made according to the technic of Flexner and Noguchi growth is very slow; after from three to seven days there is a very small amount of sediment and some turbidity in the medium around the tissue. Morphologically the organ-

* From the Memorial Institute for Infectious Diseases, Chicago.

1. Flexner and Noguchi, Jour. Exper. Med., 1913, xviii, 461. ism varies with the medium on which it is grown. In ascites dextrose broth it is gram-positive, arranged in pairs and short chains. In anaerobic culture it is variable in size, usually very small, gram-positive, arranged in pairs, clumps and chains, with an occasional large form among the minute bodies. On blood-agar plates the organism grows in small dry calonies, which produce a faint green halo and a slight degree of hemolysis. Cultures from the heart blood and from the cerebrospinal fluid after death thus far have not yielded this micrococcus but it has been obtained from the mesenteric lymph nodes.

The -organism is of low virulence for rabbits but when injected intravenously in large doses lesions of the central nervous system are produced, with paralysis which may resemble that of infantile paralysis, especially as it affects the extremities. Intracerebral injection of the organism soon after isolation has produced paralysis in the monkey. The affinity for the central system in rabbits seems to disappear after the third or fourth transplant on artificial mediums. Subcultures from a single colony of the coccus have produced paralysis in rabbits within three days after intravenous injection.

Questions that arise, the filterability of the organism when grown in various mediums, immune reactions, and other cultural characteristics, are under investigation.

In view of the accepted facts in regard to the virus of epidemic poliomyelitis it would seem most reasonable to regard the micrococcus described as a secondary invader, but further work is necessary before its significance can be fully understood. The great interest in poliomyelitis at this time and the much greater amount of material now available for the study of the disease in many places other than Chicago are the reasons for this preliminary report.

A Simple Device for Locating Foreign Bodies in Fingers. -Location in a busy clothing manufacturing district gave rise to the necessity for a simple method of determining the presence and location of foreign bodies, such as needles and splinters, in fingers. A piece of black woolen cloth 8 inches square was fastened to a piece of adhesive plaster of equal size, and in the center an oval opening was made measuring five-eighths by one-half inch. By placing this over an electric light supplied with a reflector and placing the finger over the hole, excellent transillumination is obtained, and by making pressure with a pointed instrument over the suspected area, the object can be brought out more clearly. If the field is rendered bloodless while operating, the finger may be placed over the opening and the object can be again accurately located. This device is simple, inexpensive and indestructible. It is more easily adapted than pocket flashlights, etc., to the finger, and reduces to a minimum the number of cases requiring roentgenograms. Daily use for the past six months by several workers in the accident room has proved its efficiency.-Roscoe C. Werb, A.B., M.D., Assistant House Surgeon, New York Hospital, New York.

Double Impalement.-The Medicina Contemporanea of Lisbon reports that a man in a quarry was tamping the charge in a hole he had just drilled when a premature explosion drove the long wooden rod through his neck. As he was flung up in the air, the rod broke and the other half transfixed him also, through the chest. The hemorrhage was slight and there was no subcutaneous emphysema or appreciable disturbances with breathing; the arms showed no signs of vascular or nervous trouble, and in three months the man was dismissed from the hospital. The wood was sawed off close to the skin and the rods were pulled out from the front. 